\title{
Correspondence
}

Archives of Disease in Childhood, 1971, 46, 887.

\section{Imipramine Poisoning}

Sir,

Tricyclic compounds are being used in increasing amounts both in the management of adult depression and in the treatment of childhood enuresis. Reports on cases of accidental ingestion have become more numerous in recent years. We have had recent experience in the management of a child with severe poisoning with imipramine and amitriptyline.

A 9-year-old girl, weight $24 \mathrm{~kg}$, was admitted deeply unconscious, convulsing frequently, with unrecordable blood pressure, pulse rate 50 a minute and volume very poor.

Her management was basically similar to the scheme of management outlined by Young and Galloway (1971). Convulsions were adequately controlled by intravenous diazepam (a total of $60 \mathrm{mg}$ in divided doses over a period of 36 hours), confusion and disorientation responding to chlorpromazine. The toxic cardiovascular effects were principally those of ventricular arrhythmias. During the first 12 hours after admission she had bouts of ventricular flutter, ventricular tachycardia, idioventricular rhythm, and frequent multifocal ventricular extrasystoles which were controlled by lignocaine $(80 \mathrm{mg}$ in divided doses within half an hour of admission, and thereafter a total of $2 \mathrm{~g}$ by continuous infusion over approximately 36 hours). A transvenous pacemaker was inserted (12 hours after admission) but proved of little value, and this we considered to be due to the high threshold produced by the toxic myocarditis.

There were, however, in her case several other points which we feel have not been discussed in depth in previous papers.

(1) She developed severe left ventricular failure which did not respond to the usual diuretic and oxygen therapies, but did respond to limb cuffing and the use of a cardiac bed. In her case we did not use digitalis because of the dangers involved in the presence of severe ventricular arrhythmias.

(2) The serum enzymes showed highly significant increases: aspartase transaminase (SGOT) rising to $370 \mathrm{~m} \mathrm{IU}$, alanine transaminase (SGPT) to $400 \mathrm{~m} \mathrm{IU}$, hydroxybutyrate dehydrogenase (SHBD) to $200 \mathrm{~m} \mathrm{IU}$, and the creatine kinase (CPK) to $1500 \mathrm{~m}$ IU, eventually returning to normal limits within 14 days. We have been unable to find references to such extreme changes in serum enzyme level in poisoning by tricyclic com- pounds, though Brown et al. (1970) have discussed this with reference to overdosage with hypnotic and analgesic drugs. These very significant enzyme increases in the case described are interesting and indicate both myocardial damage and generalized muscle damage. The ECG also took 14 days to return to normal.

(3) The relevance of the ease of access of this child to large amounts of imipramine and amitriptyline: the mother suffered from depression and was on long-term treatment with amitriptyline; the child was being treated with imipramine for nocturnal enuresis. We estimated that this child had taken between $1 \mathrm{~g}$ and $1.25 \mathrm{~g}$ of a mixture of imipramine and amitriptyline. She has subsequently required considerable psychiatric assessment. In retrospect the mother was probably an unsuitable person to have control over such potentially dangerous drugs in the presence of a disturbed child.

(4) The Registrar General's figures 1965-69 show that 21 children under 10 years of age in England, Wales, and Scotland, have died from accidental ingestion of tricyclic antidepressant drugs. Fraser (M.S. Fraser, 1971, personal communication) has collected information on the circumstances of death in 20 of these children. In this small group the drug involved had been prescribed for the child in 1 case, for the mother in 15 cases, for a grandparent in 3 cases, and for an adult who was not a relative in 1 case. Thus, the hypothesis that fatal antidepressant poisoning might often be due to the use of these drugs for the treatment of enuresis was not upheld.

In conclusion, we would like to emphasize the recent findings from the Registrar General's latest figures for the year 1969, showing that deaths in children due to self poisoning by tricyclic antidepressant drugs stand only second to deaths due to poisoning by salicylates. Clearly, the dangers of using these drugs in unsuitable home conditions must be kept in mind.

D. J. G. BAIN and T. TURNER
Victoria Hospital,
Kirkcaldy, Fife.

REFERENCES

Brown, S. S., Proudfoot, A. T., Raeburn, J. A., and Wright, N. (1970). Elevation of serum enzyme levels in acute poisoning. Clinical Enzymology, 2, 173.

Young, J. A., and Galloway, W. H. (1971). Treatment of severe imipramine poisoning. Archives of Disease in Childhood, 46, 353. 